\title{
Comparing the Corona Virus (COVID-19) pandemic in New Zealand and Iraq: A perspective of Preventive Medicine.
}

\author{
Dr. Vedica Sethi ${ }^{1}$ \\ ${ }^{1}$ Affiliation not available
}

October 23, 2020

1. A Preventive Medicine perspective:

2. How COVID pandemic has impacted New Zealand and their adopted policies and strategies

3. Elimination strategy

4. Mainstays of Methodolgy

5. COVID situation in Iraq, Impacting the economy of a developing country

6. Strategic implementation of preventive measures adopted by New Zealand

7. Covid- 19: Strategic Implementation of Policies under the guidance of IOM:

8. Discussion: Preparing to respond to COVID-19, what Iraq could learn from New Zealand

9. Conclusion and Outlook

10. References

1. Abstract:

2. Background. The first cases of COVID-19 pandemic were identified in people with pneumonia in Wuhan, China, in late December 2019. It is first and foremost the most publicized pandemic, which has taken the lives of many people. It has thrown everyone into doubt and has created a collective moment of contemplation about the future. The clinical enlistment organization MedWorld of New Zealand offered for resigned and low maintenance specialists to help endeavors by the health care division and Government to battle the spread of COVID-19, in New Zealand. (11"COVID-19 Pandemic in New Zealand.") Starting in April, more than 20,000 tests have been done in Iraq in general (counting the Kurdistan Region), with 1202 of them turning out positive. Of those tests, half of the,m were finished by the Kurdish Ministry of Health, which implies that the other tests were finished by the Iraqi Ministry of Health. (22"COVID-19 Pandemic in Iraq.") While KRG populace has been tried, just $0.05 \%$ of the remainder of the nation has been tried, along these lines featuring the conceivable difference between absolute positive case numbers between locales. Iraq is considered "particularly powerless against the plague due to being desolated" - by war and United Nations sanctions, and by partisan clash in the course of recent decades. This paper primarily focuses on analyzing the accessible information through research papers, peer- reviewed and non-peer reviewed to understand the pandemic affecting two different countries like New Zealand- a developed country and Iraq- a developing country.

1.2. Aim: The aim of this study is to provide information and access the current status of medical management in a developed country like New Zealand and a developing country like Iraq, based on current medical literature available. 1.3. Material used: The following review paper has considered published peer- reviewed papers and non peer-reviewed pre-print manuscripts on COVID-19 and related aspects with primary focus on preventive medicine. 1.4. Study Methodology: This retrospective view focuses on understanding the different preventive strategies implemented by the countries with different socio-economical backgrounds. 1.5. Preliminary thesis: The review paper focuses on comparing the strategic management and elimination of COVID-19, in the two countries, i.e. New Zealand and Iraq, in a public health and preventive medicine perspective. 
1. Introduction- 2.1. What is corona virus? Coronaviridae is a large family of viruses that cause mild to moderate upper-respiratory tract illnesses like the common cold. They are named for the crown-like spikes on their surfaces as seen on the electron microscope. In some cases these viruses infect the humans, which is called a spillover event and can cause several diseases. The international committee for the taxonomy of viruses has approved the naming of more than 40 corona viruses, majority of which infect animals, and lead to human transmission. The COVID-19 outbreak has brought the number of identified corona viruses that can infect humans to seven, out of which, four are community acquired. The other three are SARS-CoV, MERS-CoV and SARV-CoV-2, which has resulted in the highest mortality rate. Covid-19 or previously known as Novel corona virus is a new strain of coronavirus that first emerged in Hubei provenience in China in the late 2019. It is predominantly spread by respiratory droplets and from contact to contaminated surfaces. The spread is similar to that of influenza virus, so practicing same precautions as to prevent the influenza virus can provide protection against Covid-19. The most common symptoms are cough, severe dyspnea, fever, chills, myalgia, sore throat, congestion or runny nose. Majority of the cases have milder diseases with few having severe diseases which lead to pneumonia and respiratory failure. Deaths have generally occurred in older population, and in patients having underlining health conditions. Reports of severe cases in children are uncommon. Currently the treatment is supportive, but severe cases may require intensive care. (33Cui, Li, and Shi, "Origin and Evolution of Pathogenic Coronaviruses.")(44Masters, "The Molecular Biology of Coronaviruses.") Impact of corona virus pandemic on New Zealand: New Zealand recorded its first day of no new instances of coronavirus infection 2019 (COVID-19), more than a month after its severe lockdown started. New Zealand had recorded from less than 1200 affirmed instances of COVID19, 20 deaths. On March 23, a month to the first case reported, New Zealand focused on a disposal system. A couple of days afterward, Prime Minister Jacinda Ardern declared a public lockdown at the point when it just had 102 cases and zero deaths. Her quick decision won universal recognition, including from WHO. New Zealand's choice to seek after an end approach was a diverse way to deal with regular pandemic arranging, which has generally been in light of an alleviation model and centers around postponing the appearance of the infection, trailed by a scope of measures to level the bend of cases and passings. Michael Baker, teacher at the College of Otago's specialty of general healthcare in Wellington, who has been exhorting the New Zealand Government on its reaction. "The two greatest advantages of seeking after a disposal system is that you have barely any cases and hardly any deaths and you can get business back fully operational. The elective was that we are left with the infection and stuck between relief furthermore, concealment. Concealment is lovely terrible." (55"Coronavirus Outbreak: Live Updates on COVID-19.") While the methodology has had its experts, for Baker, the proof was overpowering that end could be accomplished. The full lockdown permitted the nation to get the major frameworks up and rushing to viably oversee fringes, furthermore, to do contact tracing, testing, and observation. Since January, more than half a million individuals have been tried in a nation of only 5 million. Testing has been centered around individuals who have presenting symptoms, with following of both close contacts and easygoing contacts. But currently, more broad testing has being presented. The Ministry of Health is in conversation with regions to organize testing of explicit networks who are at higher danger of gaining the infection such as human services laborers. Testing tests from sewerage is additionally being thought of to screen control and disposal. The reaction has additionally been one that set science, authority, and cautious language at the front line. Ardern has consistently showed up on online media, grinning and sharing parts of her own life under lockdown yet without underplaying the earnestness of the circumstance, which has served to construct open trust. Travelers from abroad are to be isolated as a major aspect of endeavors to forestall transmission in New Zealand. As New Zealand currently facilitates its limitations and its economy gradually resumes, there are conversations about how it can open up its fringes while guaranteeing that everybody is ensured, especially vulnerable populations. (66"(PDF) Coronavirus-19 Intervention Approach in New Zealand.") Impact of corona virus pandemic on Iraq: On 31 December 2019, a group of pneumonia of obscure beginning was accounted for in Wuhan City, Hubei Province of the People's Republic of China. On 11 March 2020, the World Health Organiza- 
tion's (WHO) declared that the microorganism known as the Coronavirus Disease 2019 (COVID-19), established a pandemic. By 13 March, WHO announced that the expansion in instances of COVID-19 in the Eastern Mediterranean locale, including Iraq was "of specific and incredible concern". Starting at 20 April 2020, there were 1,539 affirmed instances of COVID-19 and 82 deaths in Iraq with the quantity of affirmed cases detailed expanding. The COVID-19 episode took steps to weaken the effectively delicate framework and effect the numerous networks who are as yet defenseless and recuperating from the Islamic State in Iraq and the Levant (ISIL) emergency and ensuing monetary downturn. The center public capacities with regards to anticipation, readiness and reaction, limit with regards to general wellbeing, and the medicinal services framework has been debilitated by years of contention, sanctions, helpless administration and low interests in wellbeing. There was an absence of wellbeing workforce across various units, with many having fled Iraq, and deficiencies in basic drugs and gear. The absence of open administrations, including medicinal services, were among the variables driving distress all through 2018, especially in the southern governorates. The exhibitions and related political flimsiness brought about the abdication of the Prime Minister. At the local and worldwide level, there are proceeded and rising strains among US and Iranian intermediaries; and ISIL have additionally expressed their expectation to abuse the current emergency, which could be especially horrendous for regular citizens seeking after an arrival to normalcy. Lengthy and permeable fringes aggravate the test of overseeing dangers related with human portability and episodes; Iraq has long land and ocean fringes with Iran, Jordan, Kuwait, Saudi Arabia, Syria and Turkey, with 26 Points of Entry (PoE), including five air terminals, six ports and 15 ground intersections that convey worldwide traffic. Iraq is a country with many travelers and hence a significant number of whom are trapped in emergency and in considerably more dubious conditions. Iraq additionally has hundreds of thousands of south Asian, southeast Asian and African traveler laborers utilized in the residential, development also, administration divisions, prone to disproportionally affected by the wellbeing emergency, financial downturn and travel limitations. Travelers and evacuees in Iraq, incorporating those in outcast camps who may have residency and money related status issues, are at uplifted hazard, especially with regards to air terminal terminations, travel limitations, the stopping of worldwide resettlement program and failure to execute helped willful return and reintegration (AVRR) programming. To help stop transmission, the Government of Iraq (GoI) including the Kurdistan Regional Government (KRG) have progressively implemented bans on travelers from countries with significant COVID-19 outbreaks from entering the country, quarantine requirements and closures of the main airports in Baghdad and Erbil. (77"WHO | Iraq Health Situation Reports.")

2. A Preventive Medicine perspective:

3. How COVID pandemic has impacted New Zealand and their adopted policies and strategies: 3.1.1 Elimination strategy in New Zealand: The Government's health policy methodology in regard of the COVID-19 pandemic influencing New Zealand is elimination. That is, to apply a scope of control measures all together to stop the transmission of COVID-19 in New Zealand. Disposal doesn't mean annihilating the infection forever from New Zealand; rather it is being certain we have disposed of chains of transmission in our locale for at any rate 28 days and can successfully contain any future imported cases from abroad. It is acknowledged that this methodology will be required in the drawn out i.e., for a long time or more, contingent upon the developing the study of disease transmission and proof around the sickness and its the executives and progress with creating protected and powerful medicines and additionally antibodies. (88"New Zealand's COVID-19 Elimination Strategy | The Medical Journal of Australia.") 3.1.2. Mainstays of the methodology: Border controls are a key apparatus for halting the presentation and spread of new cases from abroad. All individuals entering New Zealand are right now secluded in an administration controlled office for at any rate 14 days on appearance, guaranteeing no new COVID-19 contaminations are presented into the more extensive populace. We envision outskirt controls being continuously loose as it gets sheltered to do as such, for instance, in the event that we are sure nations eg, Australia, have low degrees of network transmission. Further work will be expected to decide standards for this. Case surveillance allows us to recognize new cases rapidly and take proper activity. The observation plan for COVID-19 as of now incorporates testing of anybody with respiratory 
indications, and sentinel testing in the more extensive populace as a component of more extensive reconnaissance measures to give confirmation that we are not missing cases. The last will underscore testing for Māori and Pacific populaces, as they are probably going to be excessively influenced by a broad episode. Admittance to testing must be simple and value focussed. Directed populace based testing will likewise be utilized particularly in institutional settings alongside seroprevalence studies later on. A scope of knowledge sources will aid the early recognizable proof of developing bunches. Powerful contact following and quarantine is a basic piece of controlling transmission of the infection. Fruitful contact following methods 80 percent of contacts of an individual who has a positive COVID-19 test are followed and isolated inside four days of introduction to the case, to forestall ahead transmission. General wellbeing units, which routinely follow-up cases and distinguish contacts and bunches, have been financed to upgrade their capacity to do as such. A National Close Contact Service and National Contact Tracing Technology Solution have been created inside the Ministry of Health to help contract following broadly. Extra innovation stages are additionally being developed to additionally improve contact following. Group Contol measures: The most significant measures to limit the spread will stay physical removing, great cleanliness, remaining at home if wiped out and successful utilization of PPE when required. These \&quot;voluntary\&quot; measures are key to the by and large reaction and a significant level of consistence is expected to abstain from returning up ready levels later on. Study information shows proceeding with extremely high open help for the government technique and there have been just a moderately modest number of episodes of resistance to date. Guaranteeing continuous open help for these measures is basic through clear correspondence and network building activities over a scope of various age, ethnic and social gatherings. Trust in the work environment and particularly medical settings is improved by the fitting utilization of PPE. (99"(PDF) Coronavirus-19 Intervention Approach in New Zealand.")

4. COVID situation in Iraq, Impacting the economy of a developing country: IOM Iraq adds to the key needs of the IOM Global Strategic Preparedness and Response Plan. Utilizing IOM's experience working with helpless have networks, IDPs, returnees, travelers and evacuees, and solid binds with government partners at public, governorate and nearby levels, IOM will utilize a multi-sectoral reaction, utilizing an entire of-government and entire of-society approach. Where conceivable, IOM's reaction includes financial strengthening exercises also, commitment with the private segment, considering the financial impacts of this emergency and key pretended by the private division. Insurance and inability consideration will be mainstreamed to guarantee that endeavors are individuals focused, comprehensive and do no damage, and react to boundaries to administrations and data of various gatherings, including ladies, people with incapacities, more seasoned people, female-headed families and unaccompanied or isolated youngsters. Mediations may be actualized whenever the situation allows, in line with government rules; looking for inventive arrangements what's more, guaranteeing that staff and recipient prosperity is thought of and fitting preventive and defensive measures, for example, social removing, arrangement of individual preventive equipment (PPE) where required, and preparing, are utilized. (1010“IOM Iraq COVID-19 Response Plan.Pdf.”)

4. Strategic implementation of preventive measures adopted by New Zealand:

Until early March 2020, New Zealand's reaction to COVID-19 followed its current pandemic arrangement, in view of an alleviation approach for overseeing pandemic influenza3. The arrangement incorporates steps intended to slow section of the pandemic (keep it out), forestall introductory spread (stamp it out), and afterward apply physical removing measures dynamically to 'level the bend' and abstain from overpowering wellbeing administrations (oversee it). Since pandemic flu can't be contained (aside from by outrageous estimates, for example, complete fringe conclusion), there was an assumption that case and contact based administration would fall flat and the nation would definitely advance to having broad network transmission of the pandemic infection Sars-CoV-2.

Most western nations across Europe and North America were following the alleviation approach. Notwithstanding, it was performing ineffectively, with COVID-19 cases overpowering wellbeing administrations. Most nations were then changing to a concealment procedure 4 . This procedure included exceptional phys- 
ical separating and travel limitations (lockdowns) to smother infection transmission. A couple of nations were proceeding with a variant of alleviation marked 'crowd resistance' where they wanted to deal with the pace of contamination so as to abstain from overpowering the medicinal services framework and develop enough recouped and likely safe individuals in the populace to at last intrude on infection transmission. This methodology demonstrated hard to oversee and was generally relinquished (aside from maybe by Sweden).

Generally low and center salary nations could do next to no to deal with the pandemic aside from apply restricted relief measures. Vietnam was a remarkable special case, executing severe control measures including isolate, contact following, fringe controls, school terminations, and traffic limitations while case numbers were still low. Few island states, for example, Samoa, Tonga and the Cook Islands, received a prohibition approach by generally shutting their fringes to approaching voyagers.

By early March, the proof base for disposal was developing, with the expanding acknowledgment that COVID-19 isn't pandemic flu 5. A turning point was the report of the WHO joint crucial China, which affirmed that the pandemic there had been contained even after far and wide network transmission had started 6. There was additionally solid proof for the accomplishment of the end approach in Taiwan 7, Hong Kong, Singapore, and South Korea. The idea of disposal is notable to irresistible infection disease transmission specialists 8. It alludes to the nonappearance of a contamination in a nation or area. While nonappearance of sickness is a definitive objective, end models for exceptionally irresistible ailments, for example, measles consider intermittent flare-ups or imported cases gave they are gotten rid of inside a characterized timeframe 9. Conversely, destruction implies that a sickness has gotten wiped out at the worldwide level, at any rate outside research centers.

There is no settled definition for COVID-19 disposal. Fundamental reasoning proposes that such a definition would need to incorporate a characterized time of nonappearance of new cases. This measure would require a high-performing reconnaissance framework and would bar cases distinguished in showing up guests while under isolate 10. At the hour of writing in mid-May 2020, New Zealand had passed the intense period of the pandemic reaction, and could be viewed as in a pre-disposal stage. Case numbers were at low levels, with a few days without new reports. End status may take weeks or even a very long time to accomplish, and nations might move all through this state contingent upon their prosperity with containing the pandemic. (1111"Why New Zealand's COVID-19 Elimination Strategy Unlikely to Work Elsewhere | Time.")

1. Covid- 19: Strategic Implementation of Policies under the guidance of IOM: Supporting the Ministries of Health to encourage flare-up column working gatherings or boards, for example, reconnaissance, case the executives and PoE, Facilitating multisectoral coordinated effort to improve the adequacy of the COVID - 19 reaction at governorate and neighborhood levels. Arranging coordination stages for accomplices and legislative specialists to compose COVID-19 reaction exercises to help the distribution of assets and division of work and dodge duplication of administrations. Helping the Government in creating outskirt methodology planned for encouraging the coordination of return movement and the referrals of instances of migrantsat danger of gaining COVID-19, and supporting the Government in creating techniques and arrangements planned for ensuring the wellbeing of transients and a rights-based methodology. Supporting the reinforcing of between pastoral/between administration collaboration for the administration of instances of abandoned and work transients present in the public region because of the pandemic. Assisting the legislature in creating procedures and strategies for the issuance and additionally augmentation of uncommon visas for transients whose likelihood to leave the domain is restricted by the measures set up bypublic and private elements because of COVID-19; and intently helping out consular specialists of nations of root to guarantee travelers' admittance to required personality documentation and other consular administration. IOM will contribute information and investigation on populace versatility elements (locally and provincially) for a focused on and proof based reaction, including through: Establishing or supporting Population Flow Monitoring Points (FMP) at chose border focuses and key travel focuses inside the nation to comprehend and portray portability designs, key versatility tomahawks, zones of gathering and accessible administrations. Adding to IOM's DTM worldwide overall following of development limitations and different estimates 
set up at purposes of passage. Planning, checking, performing appraisals and investigating the unique circumstance and effect of COVID-19 on travelers and populaces of concern whose circumstance have been influenced by the pandemic, and imparting data to all accomplices. Preparing healthcare workers on standard precautionary measures and transmission-based precautions. Disseminating rules, work associates, and different assets to help wellbeing laborers in playing out their capacities. Arrangement of IPC supplies including cleaning supplies, disinfectants, and individual defensive equipment(PPE). Undertaking fixes, recovery and support of water, sterilization and cleanliness (WASH) offices and hand- washing stations to guarantee sufficient admittance to clean water and disinfection; remembering for casual settlements where WASH accomplices are ordinarily not present. Building up handwashing stations at the passage of the camps and settlements and at territories of assembly. This will be combined with cleanliness advancement exercises and dissemination of cleanliness units containing cleanser and cleanser (among different things), intended to engage individuals to actualize hazard correspondence messages and advance positive conduct change, in co-activity with the WASH Cluster. IOM'S Approach and Operational Strategy also included: Tracking Mobility Impacts, Risk Communication and Community Engagement (RCCE), Disease Surveillance and Addressing the socio-economic crisis of the country. (1212“IOM Iraq COVID-19 Response Plan.Pdf.")(1313"Iraq. Prevention Measures against COVID-19 in Northern Camps - UNHCR Belgium.")

2. Discussion: Preparing to respond to COVID-19, what Iraq could learn from New Zealand: As Iraq is working to "level the bend" of Covid contaminations, one has set itself an undeniably more goaloriented objective. New Zealand intends to clear out COVID-19 totally. Less than 1,500 individuals have been contaminated with the infection in the nation of right around 5 million. Just 17 have kicked the bucket. On April 24, only five new cases were affirmed. New Zealand's striking arrangement has drawn profound respect from everywhere the world. Yet, it is a little, rich island country, a long way from third world countries, who are facing the worst pandemic of 2020, with a populace that is spread out. New Zealand has a secluded island position of a moderately detached area, which implicated less early explorers from China and other tainted territories and a more drawn out time before cases began to show up. New Zealand saw its first case in February, one of the world's strictest lockdowns was implemented. In March, New Zealand reported unforgiving lockdown measures. At that point, just around 100 individuals in the nation had tried positive for the infection and nobody had at this point kicked the bucket, meanwhile Arden government implemented depicted as world's hardest border limitations. The idea behind the elimination strategy was precedeed with: Residents are needed to remain at home except if it is completely important to go out. Individuals are permitted to practice in their own neighborhoods, however swimming at the sea shore is restricted. Fringes are closed, but to residents and inhabitants, who are needed to isolate or self-separate for 14 days upon passage. Also, practically all organizations are covered. Just the organizations significant to guarantee the necessities of life, similar to general stores and drug stores, can remain open, is the official position. The lockdown measures have been combined with separation, isolates, far reaching testing for any individual who is associated with being uncovered and contact following. When a case is distinguished, that individual's nearby contacts are found and needed to self-disengage. New Zealand has regulated more than 100,000 Covid tests - a pace of 2,190 for each 100,000 individuals. By examination, South Korea-which had an a lot bigger episode and made testing generally accessible utilizing imaginative methodologies like mass drive-through test places-has a pace of 1,140 for each 100,000 individuals. Why New Zealand is remarkable? In any case, specialists concur that there are a few things pioneers far and wide can gain from how New Zealand has dealt with the emergency. New Zealand inclined up broad demonstrative testing early, made a careful cross country contact following framework, required a severe stay-at-home request, and shut its outskirts while the quantity of affirmed cases was still low. Subsequently, it figured out how to dodge the hazardous pestilences seen in different pieces of the world. Be that as it may, the best test to Iraq's COVID-19 reaction is the sensational weakening of state-society relations. Studies uncover a significant cultural doubt of Iraq's open human services establishments, because of defilement and militarization of clinical organizations. Various recordings have as of late flowed of families declining to turn over wiped out individuals - especially ladies - to clinical groups visiting family 
units with affirmed or suspected cases. The administration of Covid depends upon a plain combination between clinical foundations and security powers as the government police work together with the Ministry of Health to force curfews and uphold isolate. This implies, troublingly, a similar security foundation which brutally got serious about dissenters and common society activists is presently the teeth behind Iraq's COVID-19 reaction. Without trust among society and the political class, common society associations and dissent developments have coordinated their authoritative structure towards mindfulness raising across Iraq. Key strict specialists, for example, Grand Ayatollah Sistani have called for consistence to the time limitation and assembled beneficent foundations. (1414"IOM Iraq COVID-19 Response Plan.Pdf.")(1515Al-Malkey and Al-Sammak, "Incidence of the COVID-19 in Iraq - Implications for Travellers.")

3. Conclusion and Outlook: As clinical anthropologist Omar Dewachi noticed, the 'ethical economy of isolate'(1616"Social Economy and the COVID-19 Crisis: Current and Future Roles.") in Iraq is intensely formed by a past filled with war and its effect on the connection among individuals and the state. Albeit neighborhood and universal media frequently decipher this hesitance to go through isolate as an issue of social or ancestral standards, doubting the state leads numerous families to deny isolate on the grounds that they trust it takes after a type of capture. Iraq is a nation as of now in disturbance, experiencing aftermath the significant military acceleration between the US and Iran, mass fights requiring a conclusion to the post-2003 political framework, and a rough government crackdown executing more than 600 and injuring right around 30,000 - all directed by a divided political tip top incapable to concur upon another leader following Adil abd al-Mehdi's renunciation back in November. Coronavirus acquaints one more danger with the delicate political request, as the infection uncovered Iraq's incapable general wellbeing framework disassembled through many years of contention, debasement and helpless administration. Iraqi specialists are bending over backward to get ready for the most dire outcome imaginable, yet they do as such with tremendous auxiliary difficulties. The Ministry of Health needs enough ICU beds, HR, ventilators, and individual defensive hardware (PPE). Impeded in organization, the service is battling to handle acquisitions of hardware and meds, and a few specialists have made buys themselves. Be that as it may, singular endeavors can just venture to such an extreme the same number of Iraqi specialists are concerned the official quantities of affirmed COVID-19 cases don't mirror the intricacy of the circumstance on the ground. The service depends predominately upon patients self-introducing at assigned open medical clinics and has just barely started network based testing in territories of suspected bunches. Dependence on self-introduction requires a degree of trust among residents and state establishments, which is at a notable low. This hole in trust -17 years really taking shape - puts Iraq's COVID-19 reaction especially in danger. Iraq's horde weaknesses: Certain social and political components leave Iraq exceptionally presented to the Covid. The nation's weakness is tied straightforwardly to its social, strict and monetary interconnections with Iran, a focal point of the pandemic. Trades among Iran and Iraq are moved in two districts, with solid cross-fringe joins among Iraqi and Iranian Kurds in the north-east, and Iraqi and Iranian Shia travelers in the south. Cross-fringe dissemination of strict travelers is especially worried, as they can bring about mass ceremonial get-togethers. The high number of affirmed cases in the southern and northern peripheries of the nation places a focus on Iraq's disappointment in overseeing human services. The post-2003 government has neglected to either remake a vigorous brought together medicinal services framework, or to prepare for a federalized model. Trapped in an equivocal center between an incorporated and federalized model, coordination across areas and emergency clinics during the Covid emergency has neither reflected solid administration from Baghdad nor strong proprietorship at the governorate level. This issue is essential for a more extensive test of overseeing focus outskirts relations and federalism, which since 2003 has not worked adequately. Baghdad has given every one of the 18 territories directions on testing and treatment, yet just a modest bunch have enough assets to try them. Progressed testing limit is restricted to the five territories with WHO-endorsed focuses, with the staying 13 sending swabs to Baghdad. Be that as it may, such endeavors won't be sufficient to compensate for the absence of administration at the degree of the state. Temporarily, Iraq's clinical experts and foundations are in critical need of specialized and monetary help. In the long haul, COVID-19 is an exercise that Iraq's 
once strong open medicinal services framework needs genuine speculation and change. Coronavirus may end up being another impetus testing the 'wade through' rationale of the Iraqi political first class. Global entertainers have to a great extent been complicit in this rationale, coordinating guide and specialized help towards security powers and political partners in light of a legitimate concern for momentary dependability, and disregarding organizations, which Iraqis depend on for wellbeing, training, and prosperity. The reaction to the emergency requires collaboration and purchase in of a populace ignored by 17 years of bombed administration. This is a fundamental occasion that may push the nation to the verge, uncovering and mixing basic pressures in state-society relations.

4. References

1. "COVID-19 Pandemic in Iraq." In Wikipedia , August 22, 2020. https://en.wikipedia.org/w/index.php?title=COVID-19_pandemic_in_Iraq\&oldid=974317364.

2. "COVID-19 Pandemic in New Zealand." - In Wikipedia , September 2, $2020 . \quad$ https://en.wikipedia.org/w/index.php?title=COVID-19_pandemic_in_New_Zealand\&oldid $=976290210$.

3. Cui, Jie, Fang Li, and Zheng-Li Shi. "Origin and Evolution of Pathogenic Coronaviruses." Nature Reviews. Microbiology 17, no. 3 (2019): 181-92. https://doi.org/10.1038/s41579-018-0118-9.

4. Masters, Paul S. "The Molecular Biology of Coronaviruses." Advances in Virus Research 66 (2006): 193-292. https://doi.org/10.1016/S0065-3527(06)66005-3.

5. "Coronavirus Outbreak: Live Updates on COVID-19." Accessed September 3, 2020. https://www.modernhealthcare.com/safety-quality/coronavirus-outbreak-live-updates-covid-19.

6. ResearchGate. "(PDF) Coronavirus-19 Intervention Approach in New Zealand." Accessed September 3, 2020. https://www.researchgate.net/publication/340665413_Coronavirus-19_Intervention_Approach_in_New_Zealand.

7. "WHO T $\overline{\text { Iraq }}-$ Health Situation Reports." Accessed September 3, 2020. https://www.who.int/emergencies/crises/irq/sitreps/en/.

8. "New Zealand's COVID-19 Elimination Strategy | The Medical Journal of Australia." Accessed September 3, 2020. https://www.mja.com.au/journal/2020/new-zealands-covid-19-elimination-strategy.

9. ResearchGate. "(PDF) Coronavirus-19 Intervention Approach in New Zealand." Accessed September 3, 2020. https://www.researchgate.net/publication/340665413_Coronavirus-19_Intervention_Approach_in_New_Zealand.

10. "IOM Iraq COVID-19 Response Plan.Pdf." Accessed September 3, 2020. https://iraq.iom.int/files/IOM\%20Iraq\%20COVID-19\%20Response\%20Plan.pdf.

11. "Why New Zealand's COVID-19 Elimination Strategy Unlikely to Work Elsewhere | Time." Accessed September 3, 2020. https://time.com/5824042/new-zealand-coronavirus-elimination/.

12. "IOM Iraq COVID-19 Response Plan.Pdf." 2020. https://iraq.iom.int/files/IOM\%20Iraq\%20COVID-19\%20Response\%20Plan.pdf.

13. "Iraq. Prevention Measures against COVID-19 in Northern Camps - UNHCR Belgium." Accessed September 3, 2020. https://www.unhcr.org/be/29687-le-soutien-a-la-protection-des-plus-vulnerablescontre-le-coronavirus-est-plus-que-jamais-necessaire.html/iraq-prevention-measures-against-covid-19in-northern-camps-2.

14. "IOM Iraq COVID-19 Response Plan.Pdf." Accessed September 3, 2020. https://iraq.iom.int/files/IOM\%20Iraq\%20COVID-19\%20Response\%20Plan.pdf.

15. Al-Malkey, Maysaa Kadhim, and Maitham Ahmed Al-Sammak. "Incidence of the COVID-19 in Iraq - Implications for Travellers." Travel Medicine and Infectious Disease, May 13, 2020. https://doi.org/10.1016/j.tmaid.2020.101739.

16. "Social Economy and the COVID-19 Crisis: Current and Future Roles." Accessed September 3, 2020. http://www.oecd.org/coronavirus/policy-responses/social-economy-and-the-covid-19-crisiscurrent-and-future-roles-f904b89f/. 